\title{
Stress and Deformation Property of Geomembrane Surface Barrier for High Rock-fill Dam
}

\author{
Haimin $\mathrm{Wu}^{*}$, Zhen Zhang, and Yiming Shu \\ College of Water Conservancy and Hydropower Engineering, Hohai University, Nanjing, China
}

\begin{abstract}
Based on the direct shear test results of interface between a composite geomembrane and cushion material, nonlinear elastic, perfectly plastic model was used to describe the interface behaviors. The interface model was incorporated into the Geogrid element of a fast Lagrange analysis of continua in three dimensions $\left(\mathrm{FLAC}^{3 \mathrm{D}}\right)$ procedure through a user-defined program in the FISH. Then a geomembrane surfaced rock-fill dam on thick pervious foundation was numerically analyzed using the incorporated model. The numerical results showed that only small tension deformation can be found in the most area of geomembrane on the dam surface. However, large tension deformation of geomembrane appeared close to the anchorage in the peripheral zone of the barrier. The anchorage structure of geomembrane in this area should be carefully designed to avoid tension failure of geomembrane.
\end{abstract}

Keyword. rock-fill dam, geomembrane barrier, numerical analysis, stress-deformation behavior

\section{Introduction}

Due to better characteristics in watertight, stronger ability to adapt differential deformation, shorter construction period and lower cost than traditional barriers such as compacted clay, cement concrete and asphalt concrete as water tightness of earth and rock fill dam, geomembrane surfaced rock-fill dam is thus especially suited to be constructed on thick pervious foundation $^{[1]}$. The typical cross section of geomembrane surfaced rock-fill dam is shown in Figure 1.

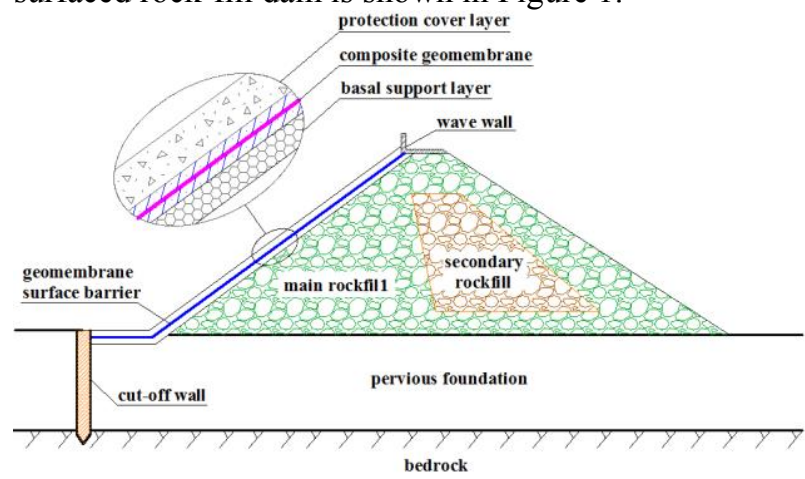

Fig. 1. Typical cross section of geomembrane surfaced rock-fill dam

The stress-deformation behavior of geomembrane surface barrier is important guarantee for security of the whole dam seepage prevention system. The stressdeformation of the geomembrane barrier for rockfill dam is usually analyzed using numerical methods including finite element method and finite differential method.
However, the key of the numerical analysis of geomembrane barrier is how to simulate the mechanical behavior of flexible geomembrane and geomembranecushions interaction. As a flexible polymer material, geomembrane is generally simulated by two-dimensional cable (bar) elements or the three-dimensional membrane elements, which can only bear tensile load rather than bending and compressing load ${ }^{[2,3]}$. However no reasonable unified calculating model has been developed to simulate the interaction of the geomembrane and cushion materials yet. The differences in elasticity modulus of geomembrane and cushion like soils are large and materials on both sides of the interface will experience discontinuous deformation like dislocation and slippage under load, thus larger shear stress is generated on the interface. The shear stress will redistribute the stress and strain of the soils near the interface on the one hand, and it is also the source of the stress and deformation of geomembrane at the same time. Therefore, the issue whether the simulation method for interaction between geomembrane and soil is proper directly affects the reliability of stress-deformation calculated results of geomembrane in working state.

At present, the researches on numerical methods of geomembrane barrier for rockfill dam are limited. Even in rare available literatures, the adopted methods are unreasonable in simulation method. The flexible cable element or membrane element was adopted to simulate the geomembrane, but no simulation of interactions between the geomembrane and cushion ${ }^{[2,4]}$. Neither flexible geomembrane element was adopted, nor interaction between the geomembrane and cushion was

\footnotetext{
* Corresponding author: wuhaimin@hhu.edu.cn
} 
considered. Only the strain of soil mass on surface of earth-rock dam was set as the strain of geomembrane, and the theoretical basis of this equivalent method is obviously inadequate ${ }^{[5-7]}$. Given all the mentioned above, the numerical method for geomembrane surface barrier of rockfill dam requires further improvement.

Aiming at the existential questions of numerical analysis method for geomembrane surface barrier of rockfill dam, proper interface constitutive model is selected to describe the mechanical behavior of geomembrane-cushion interface according to direct shear test results. The interface constitutive model was incorporated into Geogrid element of $\mathrm{FLAC}^{3 \mathrm{D}}$, and the simulation of the interaction between geomembrane and cushion is achieved. Then the incorporated interface numerical model is adopted to conduct the calculation and analysis of geomembrane barrier surfaced rockfill dam built on thick pervious foundation. The numerical results reveal the stress-deformation behavior of geomembrane barrier and corresponding design suggestions were presented.

\section{Numerical simulation method of geomembrane-cushion interaction}

\subsection{The principle of geomembrane-cushion interaction}

As the surface seepage prevention system for rockfill dam, Geomembrane was usually located between the protection cover layer and cushion (basal support layer) shown in Figure 1. Wu carried out the structural model test on geomembrane surface barrier of high rockfill dam on thick pervious foundation and reported that, when the geomembrane barrier deformed, obvious friction behavior will occur on the interface between geomembrane and cushion ${ }^{[8]}$. The friction behavior caused by the discontinuous deformation of the interface is precisely the source of shear load acting on geomembrane. So in the numerical analysis of geomembrane surface barrier, the interface need to be set between the geomembrane and cushion to simulate the friction and shear actions. The friction behavior on geomembrane-cushion interface can be simulated with the improved zero-thickness interface element ${ }^{[9]}$. In the normal direction of interface, the geomembrane is dependent upon both sides of the grid for no bending stiffness there no normal invasion and discontinuous deformation occurs e.g. separation between geomembrane and the material on both sides. In another word, node normal stresses of solid element at one side of the geomembrane passed directly to the solid element at the other side, so stress in the normal direction of interface is not involved in the iteration calculation.

\subsection{Direct shear test results of geomembrane- cushion interface}

To obtain the parameters and relation curves between shear stress and shear displacement of composite geomembrane-cushion interface, direct shear tests of the interface was conducted specifically ${ }^{[10]}$. Figure 2 shows the relation curves between shear stress and shear displacement of composite geomembrane-cushion interface. The data fitting suggests that the relationship between shear stress and shear displacement presents a typical nonlinear elastic characteristic in early stage, while plastic yield happens in later stage, and the shear stress did not increase continually with the shear displacement.

\subsection{Constitutive model of geomembrane- cushion interface}

The above interface direct shear test results indicate that the relationship between shear stress and shear displacement of this interface can be expressed by the nonlinear elastic - perfectly plastic model as shown in Figure 3. The model is mainly divided into a nonlinear elastic stage and a perfectly plastic stage. Its mathematical expression is presented as follows.

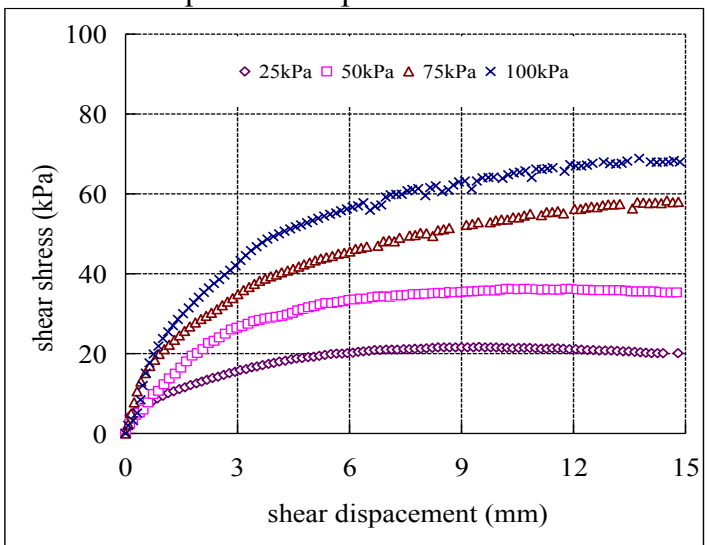

Fig. 2. Relationship of shear stress and displacement on composite geomembrane-cushion interface

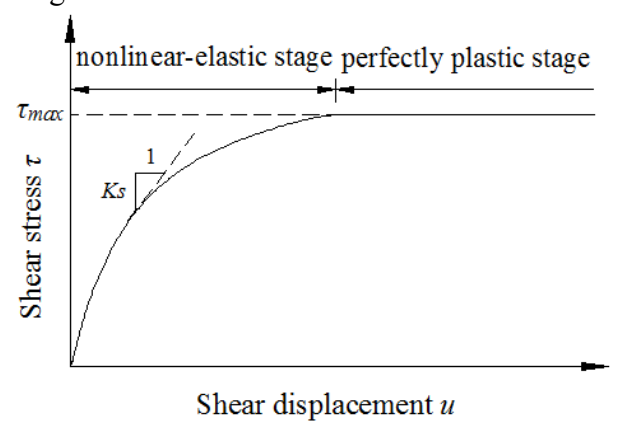

Fig. 3. Nonlinear-elastic perfectly plastic model of interface

In nonlinear elastic stage, shearing stress $\tau$ and the relative displacement $u$ of the interface between geomembrane and cushion had a nonlinear relationship, which can be expressed in nonlinear hyperbolic form ${ }^{[11]}$ :

$$
\tau=\frac{u}{a+b u}
$$

where $\mathrm{a}$ and $\mathrm{b}$ can be expressed with the following formula:

$$
a=\left(k_{1} \gamma_{w}\left(\frac{\sigma_{n}}{P a}\right)^{n}\right)^{-1}
$$




$$
b=\frac{R_{f}}{\sigma_{n} \tan \phi+c}
$$

where $k_{1}, n, R_{f}$ are the nonlinear parameters that can be derived from interface direct shear tests; $\phi, c$ are shear strength parameters of the interface; $\gamma_{w}$ is the unit weight of water; $\mathrm{Pa}$ is the atmospheric pressure; $\sigma_{n}$ is the normal pressure of the interface.

After determine the corresponding parameters by interface test, the expression of tangential shear stiffness coefficient $k_{s}$ was obtained through Equations (1), (2) and (3):

$$
K_{s}=K_{1} \cdot \gamma_{w} \cdot\left(\frac{\sigma_{n}}{P a}\right)^{n} \cdot\left[1-R_{f} \frac{\tau}{c+\sigma_{n} \cdot \tan \phi}\right]^{2}
$$

The above nonlinear elastic-perfectly plastic interface model has been incorporated into Geogrid element in $\mathrm{FLAC}^{3 \mathrm{D}}$, to realize numerical simulation of shear friction action between the flexible geomembrane and cushion material ${ }^{[12]}$. It is proved that the average interface shear stress and shear displacement relationship calculated from the incorporated interface model is in good agreement with that from theoretical model. That verified the correction and reliability of incorporated model. The interface model incorporated into Geogrid element in $\mathrm{FLAC}^{3 \mathrm{D}}$ can be used in the numerical analysis of stress-deformation behavior of geomembrane surfaced high rockfill dam on thick pervious foundation.

\section{Numerical analysis model}

\subsection{Finite difference grids of model}

A built rockfill dam was selected as a case for numerical analysis. 3D finite difference grids of dam and surface geomembrane elements are presented in Figure 4 and Figure 5, respectively. In the dam model, the dam is with a width of $10 \mathrm{~m}$ on the top, an upstream slope of $1: 1.5$, a downstream slope of 1:1.8 and a maximum height of 108 $\mathrm{m}$. The whole model is divided into 61894 solid elements, 69436 nodes; 3762 geomembrane elements, 2015 nodes; 864 interface elements and 238 nodes. Fixed constraints were applied at the bottom and roller constraints were applied on the four sides of the 3D model.

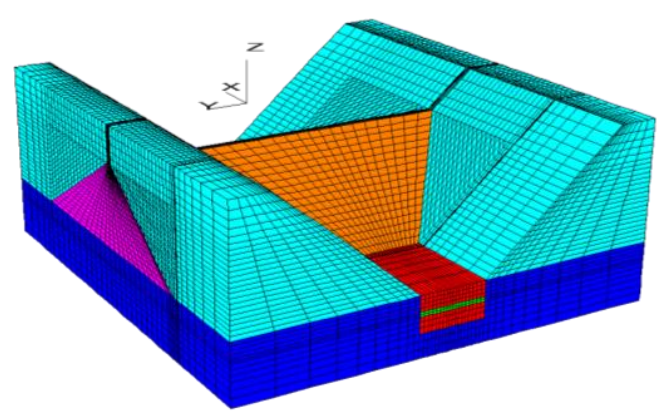

Fig. 4. Three dimensional grids of numerical model

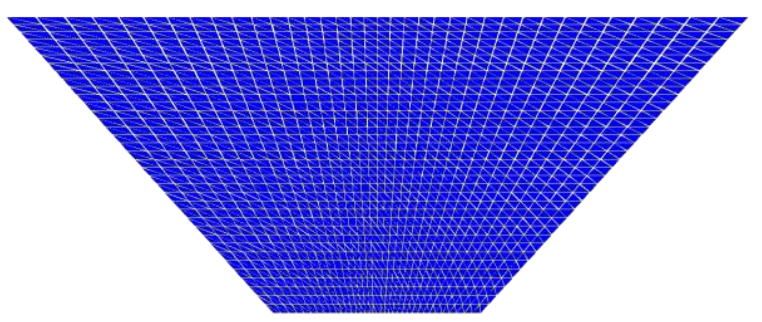

Fig. 5. Grids of geomembrane elements

\subsection{Constitutive model and parameters}

In the numerical analysis, The Duncan E-B nonlinear elastic model was adopted for soil and rock materials in the dam and foundation, while the linear elastic model was adopted for rock mass in the dam foundation and the bank slope ${ }^{[13]}$. Also the linear elastic model was adopted for materials like concrete cutoff wall, plinth, cushion and cover layers, and for geomembrane. The above nonlinear elastic-perfectly plastic interface model was adopted for the concrete- soil and rock interface and geomembrane-cushion interface.

Parameters of soil and rock, concrete structures, concrete-soil and concrete-rock interfaces were selected according to the related test data of dam project and the specific calculation parameters of soil, rock and concrete structures are shown in Table $1^{[14]}$. The calculation parameters of concrete-soil and concrete-rock interface elements are shown in Table 2. The elastic modulus and Poisson's ratio of geomembrane were selected from the tensile test results ${ }^{[15]}$; interface parameters of geomembrane-cushion interface element were selected from direct shear test results ${ }^{[10]}$. The calculation parameters of the geomembrane element and geomembrane-cushion interface element are shown in Table 3 .

\begin{tabular}{|c|c|c|c|c|c|c|c|c|c|}
\hline materials & $\gamma\left(\mathrm{kN} / \mathrm{m}^{3}\right)$ & $\mathrm{K}$ & Kur & $\mathrm{n}$ & $\mathrm{Rf}$ & $\mathrm{Kb}$ & $\mathrm{m}$ & $\varphi 0\left(^{\circ}\right)$ & $\Delta \varphi\left(^{\circ}\right)$ \\
\hline main rockfill of dam & 21.9 & 1260 & 1890 & 0.40 & 0.891 & 522 & 0.17 & 53.2 & 10.4 \\
\hline secondary rockfill of dam & 21.6 & 930 & 1395 & 0.28 & 0.823 & 415 & 0.05 & 51.4 & 9.3 \\
\hline transition layer of dam & 22.0 & 1400 & 2100 & 0.42 & 0.95 & 665 & 0.40 & 51.2 & 7.9 \\
\hline sand gravel of foundation & 21.4 & 1200 & 1800 & 0.44 & 0.84 & 450 & 0.20 & 48.5 & 7.2 \\
\hline coarse sand of foundation & 18.4 & 850 & 1275 & 0.33 & 0.745 & 405 & 0.04 & 46.5 & 3.2 \\
\hline rock in foundation and bank slope & 27.0 & 29700 & 29700 & l & l & / & / & l & l \\
\hline concrete cutoff wall & 23.5 & 315000 & 315000 & / & / & / & / & / & / \\
\hline protection cover layer & 23.5 & 280000 & 280000 & / & / & / & / & / & / \\
\hline cushion layer & 17.0 & 100 & 100 & / & / & / & l & / & / \\
\hline concrete plinth & 23.5 & 280000 & 280000 & / & l & l & / & / & l \\
\hline
\end{tabular}

Table 1 Model parameters of soil and rock materials in the dam and foundation 
Table 2 Model parameters of concrete-soil and rock interface elements

\begin{tabular}{|c|c|c|c|c|c|c|c|c|}
\hline \multirow{2}{*}{$K$} & \multirow{2}{*}{$\mathrm{n}$} & \multirow{2}{*}{$R_{f}$} & \multirow{2}{*}{$\begin{array}{c}c \\
(\mathrm{~Pa})\end{array}$} & \multirow{2}{*}{$\begin{array}{l}\varphi \\
\left(^{\circ}\right)\end{array}$} & \multicolumn{4}{|c|}{$k_{\mathrm{n}}\left(\mathrm{kN} / \mathrm{m}^{3}\right)$} \\
\hline & & & & & & when compressed & & when tensile \\
\hline 1400 & 0.60 & 0.86 & 5000 & 9.0 & & $1 \times 108$ & & 100 \\
\hline \multicolumn{9}{|c|}{ Table 3 Model parameters of geomembrane elements and geomembrane-cushion interface } \\
\hline $\begin{array}{c}\mathrm{E} \\
(\mathrm{MPa})\end{array}$ & & $v$ & $K$ & & $\mathrm{n}$ & $R_{f}$ & $\begin{array}{c}c \\
(\mathrm{~Pa})\end{array}$ & $\begin{array}{l}\varphi \\
\left(^{\circ}\right)\end{array}$ \\
\hline 20 & & 0.475 & 2676 & & 0.21 & 0.89 & 5630 & 32.9 \\
\hline
\end{tabular}

\subsection{The calculation procedure}

The whole calculation process is divided into three steps: firstly, build a dam foundation and rock mass of both sides, calculate the initial force, and then clear the displacement; secondly, establish the dam by layer, and simulate the layered roller compaction construction of the dam with 9 classes of the filling construction in all; thirdly, clear the dam displacement upon the completion of filling construction of the dam, save the stress, establish geomembrane surface battier on the dam like cushion, geomembrane and protection cover elements, and then exert water pressure load on the upstream surface of dam, foundation, bank slopes and concrete cutoff wall to perform the calculations.

\section{Results and discussion}

\subsection{Numerical calculation results}

\subsubsection{Deformation of dam and foundation}

Figure 6 shows the distribution of incremental vertical displacement of dam and foundation caused by water pressure. As shown in the figure, under the water pressure load, the settlement of dam and foundation decreased from upstream to downstream. Maximum is in the foundation surface near downstream side of concrete cutoff wall, and maximum settlement was $-47.9 \mathrm{~cm}$. The settlement at the top of concrete cutoff wall was $-15 \mathrm{~cm}$. So the maximum differential settlement between the top of concrete cutoff wall and dam foundation was $32.9 \mathrm{~cm}$.

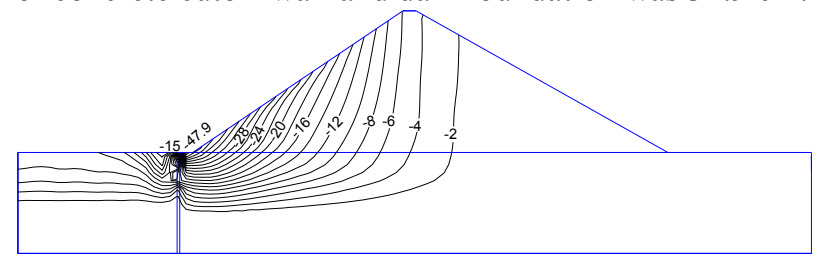

Fig.6. Increment of vertical displacement of dam and foundation caused by water pressure $(\mathrm{cm})$

Figure 7 shows the distribution of the incremental horizontal displacement of dam and foundation caused by water pressure. As shown in the figure, the horizontal deformation of the whole dam and foundation caused by water pressure decreased from upstream to downstream. The maximum incremental horizontal displacement is in the upstream dam toe, with maximum of $34.8 \mathrm{~cm}$.

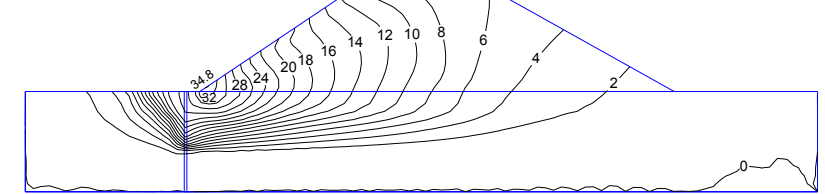

Fig.7. Increment of horizontal displacement of dam and foundation caused by water pressure $(\mathrm{cm})$

\subsubsection{Principal stresses of geomembrane}

Figure 8 shows the distribution of the major and minor principal stresses of geomembrane on the dam. As shown in the figure, the major and minor principal stresses of geomembrane on the dam show symmetrical distribution along a central axis of riverbed. Principal stress is larger at the lower part of bank slope and near the dam toe. Principal stress at the center of dam surface is small. Maximum of major principal stress is $3.8 \mathrm{MPa}$, and the maximum of minor principal stress is $1.8 \mathrm{MPa}$, both of which are around the corner of bank slope. The maximum of major and minor principal stresses near the center of dam toe are 1.2 $\mathrm{MPa}$ and $0.4 \mathrm{MPa}$ respectively, while the major and minor principal stresses at most parts of the dam surface are less than $0.05 \mathrm{MPa}$ and 0.01 $\mathrm{MPa}$, respectively.

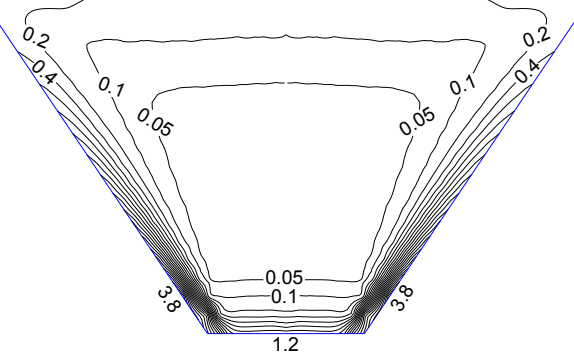

(a) Maximum principal stress

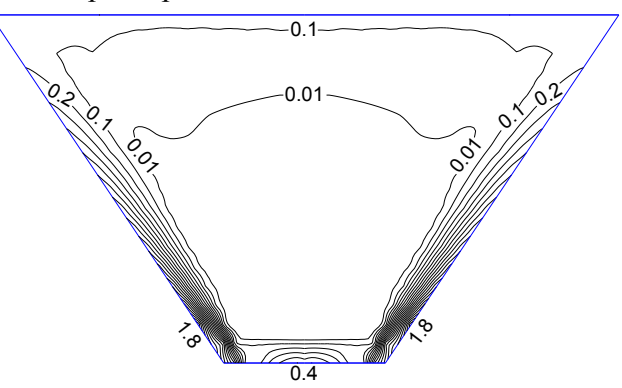

(b) Minimum principal stress

Fig.8. Maximum and Minimum principal stresses of geomembrane $(\mathrm{MPa})$ 


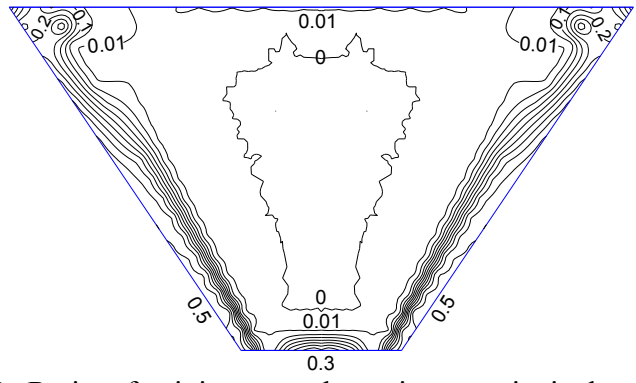

Fig. 9. Ratio of minimum and maximum principal stress of geomembrane

Figure 9 shows the distribution of the biaxial principal stress ratio, which is equal to major principal stresses divided by minor principal stresses of geomembrane on the dam. The biaxial principal stress ratio of geomembrane on the dam also shows symmetrical distribution along a central axis of riverbed. The biaxial principal stress ratio is larger at the lower part of bank slope and near the dam toe, which is small at center of dam surface. Maximum of biaxial principal stress ratio is 0.5 , and is around the corner of bank slope. The maximum of biaxial principal stresses ratio near the center of dam toe is 0.3 , while the biaxial principal stresses ratio at most parts of the dam surface is less than 0.01 or near 0

\subsubsection{Principal strain of geomembrane}

Figure 10 shows the distribution of the major and minor principal strains of geomembrane. As shown in the figure, the distributions of major principal strains are similar with major principal stresses above, and the main deformation also focused at the lower part of bank slope and near the dam toe. The maximum of major principal strain is around the corner of bank slope and is $14.95 \%$; the maximum of major principal strain near the center of dam toe is $5 \%$; major principal strains at most parts of the dam surface are less than $0.25 \%$; The minor principal strain at the upper part of bank slope is relatively evenly

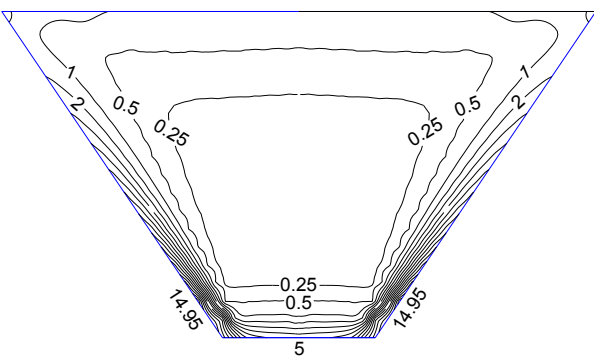

(a) Maximum principal strains

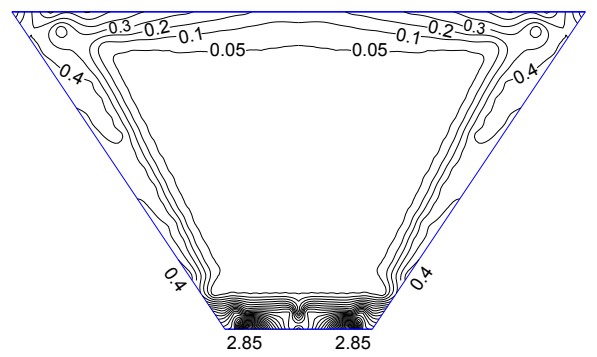

(b) Minimum principal strains

Fig.10. Maximum and Maximum principal strains of geomembrane $(\%)$ distributed, and the maximum is $0.4 \%$; while the distribution of minor principal strain near the center of dam toe is quite uneven, and the maximum is $2.85 \%$.

\subsection{Analysis and discussion}

It is revealed from the distribution of principal stresses and strains of geomembrane obtained by numerical analysis that, the stress and strain values of geomembrane at the dam surface is small and its distribution is even, the maximum tensile strain on the dam is only $0.25 \%$; but serious stress concentration of geomembrane appears at the bank slope and near the dam toe, and the principal strain values are larger. The maximum tensile strain is $14.95 \%$, and parts of the larger stress and strain were located in the bank slope and near anchorage at the corner of dam foundation. The differential deformation between rigid anchoring structure and dam, foundation were the main causes of the stress concentration and great tensile stain near anchorage of geomembrane.

Addition to the principle stress and strain, distribution of biaxial principal stress ratio suggests that the difference in biaxial principal stress is large, maximum biaxial principal stress ratio in the bank slope and near anchorage was only 0.5 , namely the ratios of the major principal stress to minor principal stress were larger than 2. The biaxial tensile test result of the geomembrane conducted by $\mathrm{Wu}$ indicates that, when the biaxial principal stress ratio of the geomembrane is too large or too small, where the ultimate strain of geomembrane is small, ultimate tensile failure is more likely to appear ${ }^{[8]}$. It can be deduced that the tensile failure easily happened to geomembrane at the corner between bank slope and dam toe.

Principal stress ratio at the dam surface is close to or equal to 0 , and the difference in biaxial principal stress is bigger whereas the principal stress at the dam surface is very small. Although the principal stress in most parts of the dam surface is smaller, the geomembrane is still safe.

\section{Conclusions}

The interface model incorporated into Geogrid element in FLAC $^{3 \mathrm{D}}$ is employed in the numerical analysis of stress-deformation behavior of geomembrane surfaced high rockfill dam built on thick pervious foundation. The main conclusions are as follows:

(1) Due to water pressure load, large differential settlement between the dam foundation and concrete cutoff wall appears. As the area is the anchorage of geomembrane, the differential settlement easily leads to the stress concentration and tensile deformation of the geomembrane.

(2) The principal strains of the geomembrane are mainly in the bottom of bank slope and near dam toe. The maximum tensile strain is up to $14.95 \%$ around the corner near the bottom of bank slope, while the major principal strains at most parts of the dam surface are less than $0.25 \%$. 
(3) For the geomembrane surfaced rockfill dam built on thick pervious foundation, deformation of most geomembrane on the dam surface is small, but larger tensile strain of the geomembrane appears in nearby anchoring area. Therefore, special anchoring structure design is required in the peripheral area of geomembrane, where nearby the bank slope and dam toe. Through rational anchoring structure, the large tensile deformation of the geomembrane caused by differential deformation near bank slope and dam toe can be eliminated, thus ensuring the security of geomembrane barrier of the dam.

\section{Acknowledgements}

The present research was financially Funded by the Fundamental Research Funds for the Central Universities (No. 2016B00214), Natural Science Foundation of China (Nos. 51409083 and 51379069), and the Priority Academic Program Development of Jiangsu Higher Education Institutions. Authors would like to thank the anonymous referees whose comments helped us improve the presentation of this research.

\section{References}

1. D. Cazzuffi, J.P. Giroud, A. Scuero, G. Vaschetti. Geosynthetic barriers systems for dams, 9th International Conference on Geosynthetics, Guarujá, Brazil, 1265-1268 (2010)

2. Y.M. Shu, G.C. Gu. The FEM analysis of the rockfill dam using geomembrane as central barrier[J]. Journal of Hohai University, 16(S1), 79-91 (1988) (in Chinese)

3. Y.L. Xing, Y.M. Shu, J.F. Hua, Y.H. Li, W.Y. Zhou. Effect of geomembrane and core-wall united impervious system on arch effect of core-wall in high earth-rock dams[J]. JOURNAL OF HOHAI UNIVERSITY (NATURAL SCIENCES), 35(04), 456-459 (2007) (in Chinese)

4. W.J. Cen, C.S. Shen, J.W. Tong. Study of on $\mathrm{f}$ construction behavior feasibility of composite geomembrane rockfill dam on thick alluvium deposit[J]. ROCK AND SOIL MECHANICS, 30(1), 175-180 (2009) (in Chinese)

5. T.K. Tao, D.F. Li, Yanjun. Coupling calculation of stress and seepage characeristic in composite geomembrane core-rock dams $[\mathrm{J}]$. Hydro-Science and Engineering, 4, 374-383 (1995) (in Chinese)

6. G.C. Gu, C.S. Shen, J.B. Wu. Reinforcement of Shibianyu asphalt concrete slope-wall rockfill dam with composite geomembrane[J]. ADVANCES IN SCIENCE AND TECHNOLOGY OF WATER RESOURCES, 24(1), 10-14. (2004) (in Chinese)

7. J. Yan, T.K. Tao, L.F. Li. Optimum design of a geomembrane aniseepage layer[J]. Hydro-
Science and Engineering, 4, 45-48 (2001) (in Chinese)

8. H.M. Wu. Research on Key Problems in Geomembrane Surface Barrier of Rock-fill Dam on Thick Pervious Foundation: Doctoral thesis, Nanjing, Hohai University. (2013) (in Chinese)

9. R.E. Goodman, R.L. Taylor, T.L. Brecke. A model for the mechanics of jointed rock. Journal of Soil Mechanics And Foundation Division. ASCE, 94 (3), 637-659 (1968)

10. H.M. Wu, Y.M. Shu, L.J. Dai, Z.M. Teng. Mechanical Behavior of Interface between Composite Geomembrane and Permeable Cushion Material, Advances in Materials Science and Engineering, vol. 2014, Article ID 184359, 9 (2014)

11. J.M. Duncan, C.Y. Chan. Nonlinear analysis of stress and strain in soils. Journal of Soil Mechanics and Foundations Division, 96 (5), 1629-1653 (1970)

12. H.M. Wu, Y.M. Shu, L.J. Dai, Z.M. Teng. IMPLEMENTATION AND VERIFICATION OF A GEOSYNTHETIC-SOIL INTERFACE CONSTITUTIVE MODEL IN THE GEOGRID ELEMENT OF FLAC(3D), ACTA GEOTECHNICA SLOVENICA, 12 (01), 26-35 (2015)

13. G.W. Clough. Finite element analyses of retaining wall behavior[J]. Journal of Soil Mechanics \& Foundation Engineering, 97(12), 1657-1673 (1971)

14. Z.P. Xu. Study on stress and deformation properties of high concrete face rock-fill dam: Doctoral thesis. Beijing, China Institute of Water Resources and Hydropower Research. (2005) (in Chinese)

15. H.M. Wu, Y.M. Shu. Stress-Stain Response of PVC Geomembrane under Uniaxial Tension Test. Advanced Materials Research, 936, 15821586 (2014) 